\title{
Thyrohyoid Muscle
}

National Cancer Institute

\section{Source}

National Cancer Institute. Thyrohyoid Muscle. NCI Thesaurus. Code C53178.

A skeletal muscle belonging to the infrahyoid muscle group, located in the anterior part of the neck, with its origin on the thyroid cartilage and its insertion on the hyoid bone; it functions to depress the hyoid bone and elevate the larynx during swallowing and speaking. 